\title{
COST REDUCTION AND ENERGY SAVING BY IMPLEMENTING OPTIMAL REVAMPING FOR A BLAST FURNACE'S MOTOR BLOWER
}

\author{
WOOSUNG SHIM \& SANGHYUN OH \\ Energy Department in POSCO Pohang Steel Works, Korea Institute of Energy Research, South Korea
}

\begin{abstract}
Following the launch of the new government, declaration of the de-nuclear, de-coal power plant changed Korea's energy strategy. The demand for renewable energy or energy saving technology is expected to increase significantly in the future. In the absence of clear alternatives to replace nuclear or large capacity coal fired power plants, we expect the industry's electricity charge will continue to rise. The integrated steel mill is the mass scaled equipment industry, POSCO and is now using up to $8 \%$ of Korea's energy consumption. Considering the government's recent policy and in order to enhance the profitability of the company, we are actively promoting activities such as increasing efficiency and reducing energy consumption. The core of the steel mill is the blast furnace, and the motor blower supplies large capacity, high pressurized air to the blast furnace. Using the large capacity motor as a power source, it accounts for $10 \%$ of the steel mill's electrical consumption. When the blower blade's failure, due to being used for such a long time, we implemented partial revamping that can minimize the cost and the construction period. As a result of successful revamping, we could contribute to minimize the payback period and improve the profitability of the steel mill.
\end{abstract}

Keywords: integrated steel mill, motor blower, partial revamping, efficiency, energy saving.

\section{INTRODUCTION}

\subsection{Characteristics of steel industry}

The steel industry provides the essential materials for the industry by producing steel, From small clips to aircraft, steel. They have a close relationship with human life and contribute greatly to the development of human civilization. The characteristics of the steel industry are as follows.

1. There is a very large association between the front and rear industries.

2. The scale of the integrated steel mill itself is very large.

3. Integrated steel mill, represented by a blast furnace, is difficult to flexibly control production.

4. Steel mills are mass energy-consuming industries, and many processes consist of high temperature, high pressure operations (For example, POSCO consumes $8 \%$ of Korea's total energy and pays 1.4 billion dollars for electricity).

Recently, the low growth rate of the steel industry is continuing worldwide. In such a situation, steel industry restructuring is proceeding, transforming from past quantitative growth strategy to optimal production system. Also, it is expected that the cost of the energy burden will be increased following the launch of the new government's declaration of denuclear, de-coal power plant in Korea. Our company is also making a lot of effort to reduce the energy used in the process. 


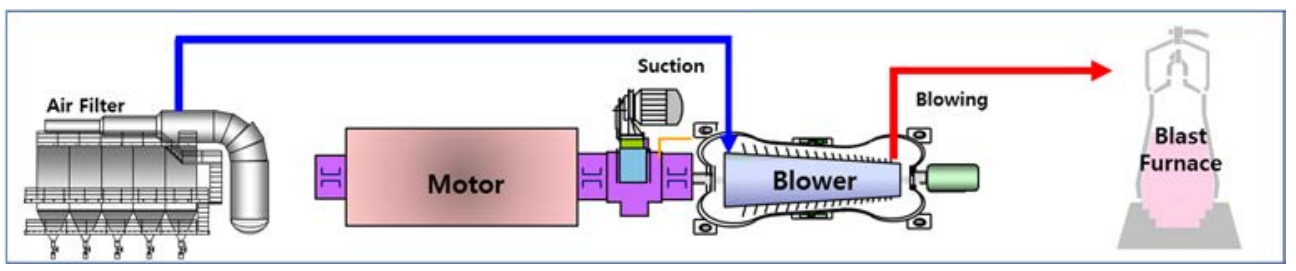

Figure 1: Motor blower process for blast furnace.

\subsection{About POSCO}

Established in 1968, POSCO provided essential materials to automobile, construction, and ship building companies, which are the representative industries of Korea. We played an important role in driving the industrialization in Korea.

POSCO has two integrated steel mills in Pohang and Gwangyang province, and participated in construction of overseas steel mills such as Indonesia and Brazil. The production of crude pig iron was 42 million tons in 2016 , which is the world's $4^{\text {th }}$ largest production quantity.

\subsection{Blast furnace and motor blower in steel mill}

Blast furnace produces pig iron by reducing the iron ore using cokes and pulverized coal. The blast furnace is the core facility in the steel mill, all the plants' operation in steel mill are synchronized with blast furnace's production plan. The Motor blower is an important facility which supplies high capacity and high pressured air to the blast furnace's hot stove. The axical compressor is operated using a large capacity synchro motor as a power source. A lot of electricity is essential for operating the motor blower, and it is the 2nd largest amount in the steel mill.

\section{REVAMING PLAN FOR MOTOR BLOWER}

\subsection{Revamping opportunity: blower blade's fatigue failure}

We have 3 motor blowers (1-3MB) for Numbers 3 and 4 Blast furnaces, two machines are in operation, and the other is on standby. They have been running for 37-40 years without replacement after it's installation in 1978 and 1980.

In April 2016, it was confirmed that the machine reached the limit of life due to the blade's fatigue failure accident after running for such a long time (We overlooked the life time, because it's not a harsh operating condition compared to other facilities) looking closely at the blade's fracture surface, the typical mark of fatigue failure, the beach mark was identified. The breakage mechanism was considered to be the combination of high cycle fatigue due to the

Table 1: Motor blower's specification for No. 3, 4 blast furnace.

\begin{tabular}{|c|c|c|c|}
\hline Motor Blower & Blower Flow & Motor Capacity & Installation \\
\cline { 1 - 1 } $1,2 \mathrm{MB}$ & \multirow{2}{*}{$8,600 \mathrm{Nm}^{3} / \mathrm{min} \times 5.1 \mathrm{~kg} / \mathrm{cm}^{2}$} & $49 \mathrm{MW}$ & 1978 \\
\cline { 1 - 2 } & & & 1981 \\
\hline
\end{tabular}



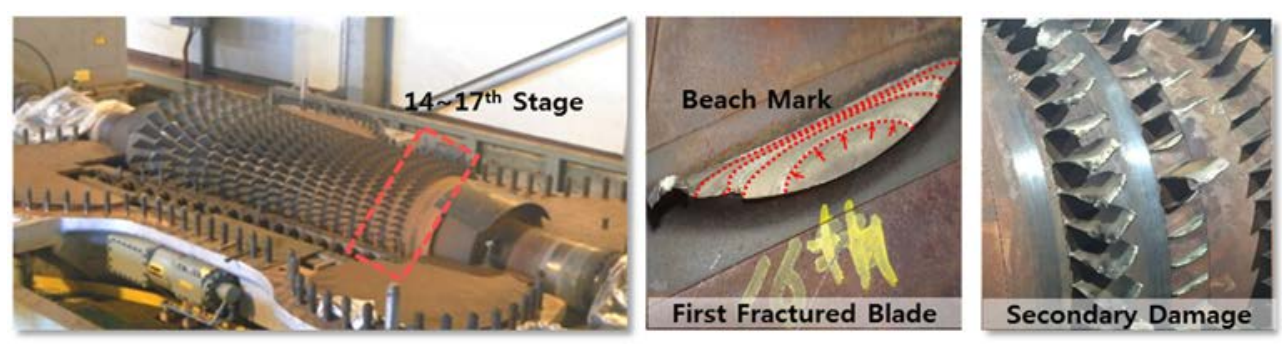

Figure 2: Fatigue fracture of blower blade.

repetitive shutdown and creep damage because of the operation temperature (250-300 degrees celsius).

We judged that the 1-2MB had reached its mechanical life time, because of the operating conditions which are the same as $3 \mathrm{MB}$ and operated for more than 40 years. For those reasons, we planned to revamp the motor blowers in Pohang steel works.

\subsection{Preconditions for optimal revamping}

For optimal revamping, we focused on the following three aspects: revamping period, total cost and efficiency improvement (energy saving etc.).

First of all, minimization of the revamping period is essential, because it is a direct connected facility to the blast furnace. Absence of spare machine can affect blast furnace's operation, which means reduced production in steel mills. No.3 Blast Furnace's revamping is planned in the first half of 2017. If we can take advantage of this period, we can lessen the burden because of the absence of the spare machine.

Next, it is necessary to minimize the cost of revamping due to the recent financial pressure caused by regression in the steel industry. We could reduce cost and delivery time buying full advantage of existing parts which is not directly related to performance and deterioration. Finally, our motor blower was installed about 40 years ago, it is technically half a century lag behind model. We need to reinforce the machine, enhance the efficiency applying brand new compressor technology. Applying the latest compressor technology, such as a blade geometry shape which would improve and decrease the weight by reducing the blade stage, we expect to improve the machine's robustness and performance. Based on the above basic preconditions, we implemented the revamping project.

\section{IMPLEMENTING THE REVAMPING}

\subsection{Surveys on relevant market and manufacturer}

With the above preconditions, we contacted the original manufacturer and the world's leading compressor maker. Specification meeting results with them are as follows.

Company $\mathrm{C}$ (Original maker): holds original manufacturing drawings, but design improvement is not possible for the performance improvement.

Company A, B: reverse engineering and design improvement was possible, so energy saving effect through enhancing the efficiency or performance seems possible. However, company B couldn't meet the requested performance. Due to company B's under required specification, there was competition between company A and B. Company A had lots of 
Table 2: Suggested specification by manufacturers.

\begin{tabular}{|c|c|c|c|c|c|c|}
\hline \multicolumn{4}{|c|}{ Preconditions \& Requirements } & Company A & Company B & $\begin{array}{c}\text { Company } \\
\text { C }\end{array}$ \\
\hline Period & \multicolumn{2}{|c|}{ Delivery } & A.S.A.P & '17.3 & '17.4 & '17.5 \\
\hline \multirow{3}{*}{ Cost } & \multirow{2}{*}{$\begin{array}{l}\text { Inner } \\
\text { part }\end{array}$} & $\begin{array}{l}\text { Rotor \& } \\
\text { Stator }\end{array}$ & Exchange & $\begin{array}{c}\text { Exchange } \\
\text { (New } \\
\text { design) }\end{array}$ & $\begin{array}{c}\text { Exchange } \\
\text { (New } \\
\text { design) }\end{array}$ & $\begin{array}{c}\text { Exchange } \\
\text { (Same } \\
\text { design) }\end{array}$ \\
\hline & & $\begin{array}{c}\text { Blade } \\
(17 \text { stage } \\
)\end{array}$ & Exchange & $\begin{array}{l}\text { Exchange } \\
\text { (14stage) }\end{array}$ & $\begin{array}{l}\text { Exchange } \\
(14 \text { stage })\end{array}$ & $\begin{array}{l}\text { Exchange } \\
\text { (17stage) }\end{array}$ \\
\hline & \multicolumn{2}{|c|}{$\begin{array}{l}\text { Outer Casing } \\
\text { Piping, etc. }\end{array}$} & Reuse & \multicolumn{3}{|c|}{ Reuse } \\
\hline \multicolumn{3}{|c|}{ Efficiency } & $\begin{array}{l}\text { The higher } \\
\text { The better }\end{array}$ & $3.6 \%$ & $3.7 \%$ & $0 \%$ \\
\hline \multicolumn{3}{|c|}{$\begin{array}{l}\text { Guaranteed Performance } \\
\left(\text { Max Air Volume at } 35^{\circ} \mathrm{C}\right)\end{array}$} & $\begin{array}{c}8,600 \mathrm{Nm}^{3} / \mathrm{mi} \\
\mathrm{n}\end{array}$ & 8,600 & 8,080 & 8,600 \\
\hline \multicolumn{3}{|c|}{ Final Judgment } & - & Satisfying & Unachieved & Satisfying \\
\hline
\end{tabular}

successful experience in the revamping projects, but company $\mathrm{C}$ withdrew from the largecapacity blower business in 1980s.

Finally, Company A was selected as our revamping partner after comprehensive judging, such as possibility of delivery within the required period, cost reduction by utilizing old parts and improving the efficiency. Fortunately, blast furnace's revamping was planned from February to June in 2017 (Revamping cycle 15-20 years, duration about 3 months). To make the most of this period we pre-ordered the maker to commence manufacturing, finally we could minimize the administrative loss.

\subsection{Revamping details}

The revamping period:

We planned to complete 2 machines within the blast furnace's revamping period, but encountered several unexpected problems because of partial revamping, it took time to solve these problems. Initially implemented $2 \mathrm{MB}$ took approximately 2 times longer than our original schedule.

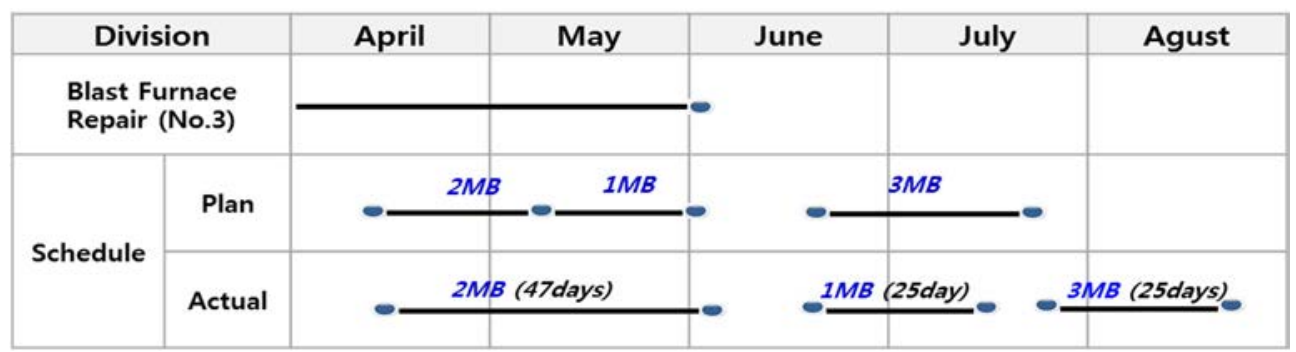

Figure 3: Motor blower revamping schedule. 


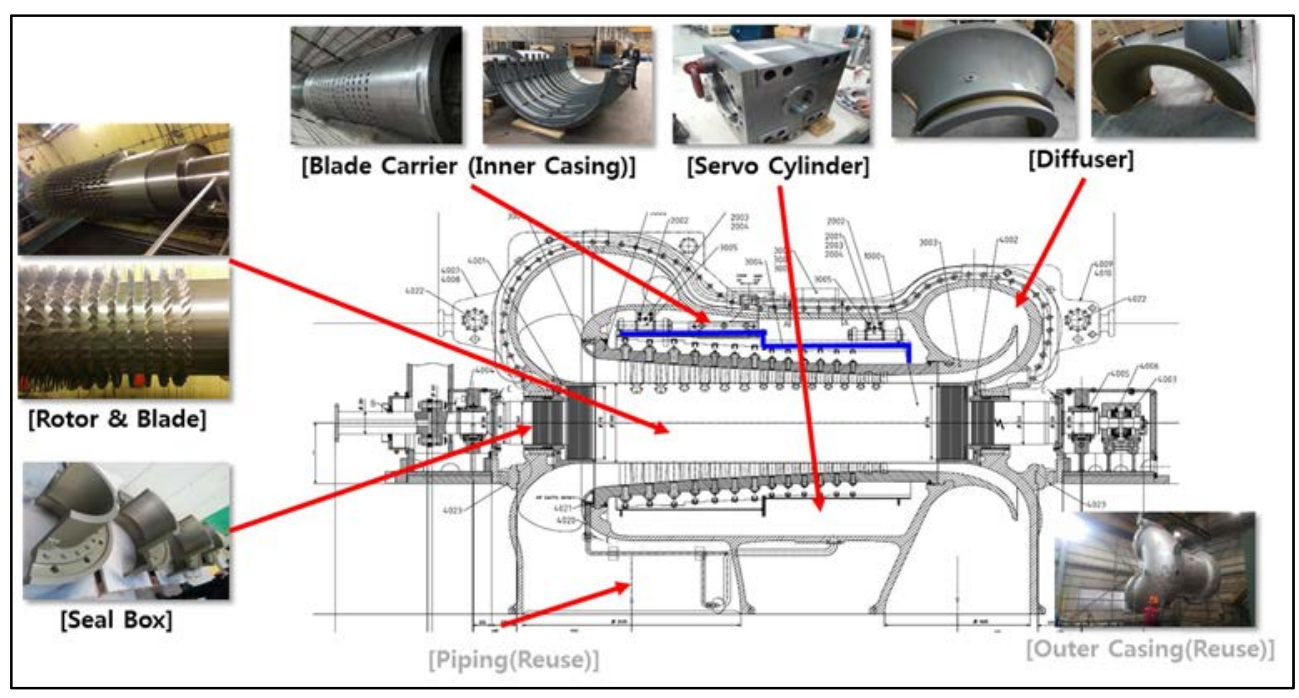

Figure 4: Motor blower replacement.

Targeted parts:

Except motor and electric/instrumentation parts which were renewed recently, The Blower's mechanical parts were the main target for this project such as the rotor, rotor blade, stage blade, inner casing and diffuser, etc. Base foundation, outer casing, and piping were excluded. Outer casing, which has very little influence from temperature and pressure, was subjected to non-destructive testing. As a result of the non-destructive test, we confirmed that there was no problems with the outer casing. By utilizing outer casing, we could save 1.8 million dollars. Motor consuming power has been decreased due to efficiency improvement by applying weight reduction and gap minimization technology through reducing the number of blades (existing 17 stages $\rightarrow$ improved 14 stages) compared to the former machine. Coating was applied to improve the corrosion and mechanical resistance in the weak $1^{\text {st }}$ and $2^{\text {nd }}$ stage blades which was due to foreign particle and moisture intake.

Difficulties during revamping:

Although maker's design ability, revamping experience and POSOC's field experiences were abundant, we encountered unexpected problems see below

- Abnormal stress and deformation due to long term usage.

- Alignment and thermal expansion ratio differences between new and old parts.

- Problems during disassembly and assembly.

As a representative example, there was a rubbing problem during the first operation after revamping was completed. The first phenomenon was found through VMS (Vibration Monitoring System) vibration analysis, typical phenomena such as variation of phase and amplitude show the evident rubbing problem. To prevent the breakage of the machine, it was stopped immediately. After disassembling the machine, there was heavy friction between the new (rot seal strip, rotating part) and old parts (casing seal box, stationary part). As it was 


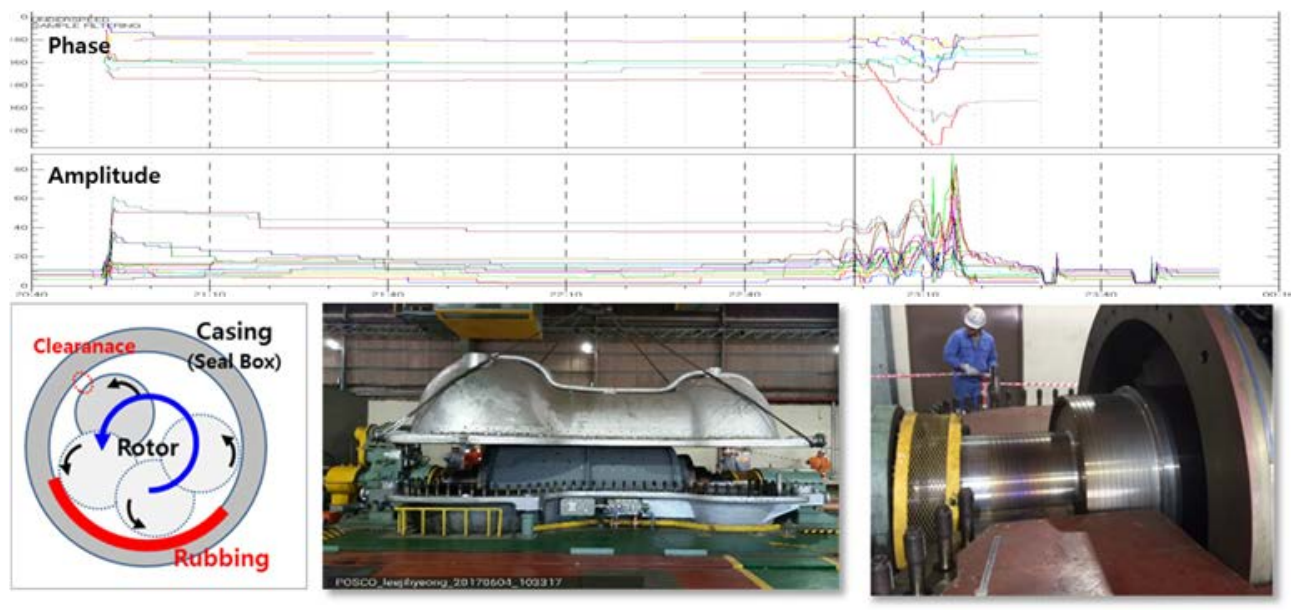

Figure 5: Rubbing during first operation.

designed to minimize the gap to enhance the blower's efficiency, it seemed that rubbing occurred in the direction of radial due to the difference of thermal expansion ratio.

It was solved by adjusting the upper and lower clearance gap of the rotor and seal box.

\subsection{Revamping's benefits}

As a result of the partial revamping, the blowers efficiency increased by $5 \%$, and the motor power consumption decreased $3 \mathrm{MW}$, so annual electricity cost can be saved by 1.8 million dollars per machine. We also learnt that we can save money and shorten the construction period by successful partial revamping, but the project itself may become uncertain without sufficient surveys in advance and the appropriate counter measures for the problems that we encountered.

\section{CONCLUSIONS}

Motor blower which are an essential facility for No.3,4 blast furnaces were partially revamped in POSCO's Pohang works. It mainly focused on reducing the cost, construction period and enhancing the efficiency. Although there were some difficulties in the construction and commissioning stage due to the partial replacement, we collaborated wisely with the manufacturer, the following accomplishments were achieved.

- $\quad$ Reduced construction period by $50 \%$ (50 days $\rightarrow 25$ days).

- Reduced cost by more than 1.8 million dollars through optimal replacement of parts.

- Reduced electricity cost for motor through improved blower's efficiency, 1.8 million dollars per each machine. (3.6million dollars per year).

In the future, Pohang works will actively implement partial revamping projects for the facilities that have been used more than 30-40 years. Thus, we will continue to maintain our technological and cost competitiveness in the steel industry. (Partial revamping project is also undergoing for the power plant). 